This is the peer reviewed version of the following article:

Vázquez, J. J., Panadero, S., \& García-Perez, C. (2020). Immigrant women living homeless in Madrid (Spain). American Journal of Orthopsychiatry, 90(5), 633-643,

which has been published in final form at:

http://dx.doi.org/10.1037/ort0000488

This article may be used for non-commercial purposes in accordance with American Psychological Association and Conditions for Use of Self-Archived Versions. 
Vázquez, J. J., Panadero, S., \& García-Perez, C. (2020). Immigrant women living homeless in Madrid (Spain). American Journal of Orthopsychiatry, 90(5), 633-643.

DOI: doi.org/10.1037/ort0000488

(C) 2016 American Psychological Association. This paper is not the copy of record and may not exactly replicate the authoritative document published in the APA journal. Please do not copy or cite without authors permission. The final article will be available, upon publication, at: $10.1037 /$ ort0000488.

\section{IMMIGRANT WOMEN LIVING HOMELESS IN MADRID (SPAIN).}

\section{José Juan Vázquez}

Universidad de Alcalá

Sonia Panadero

Universidad Complutense de Madrid

Carmelo García-Perez

Universidad de Alcalá

Corresponding author: José Juan Vázquez, Ph.D. Área de Psicología Social. Facultad de Documentación. Universidad de Alcalá. Aulario María de Guzmán. C/ San Cirilo, s/n. 28801 Alcalá de Henares. Madrid. España. E-mail: jj.vazquez@uah.es.

Funding statement: This research was supported by the Agencia Estatal de Investigación of the Ministerio de Economía, Industria y Competitividad of Spain (Reference: FEM2016-75317$\mathrm{R})$. 


\begin{abstract}
Homeless people are one of the most obvious embodiments of the phenomenon of social exclusion, and homeless immigrants and homeless women are considered two particularly vulnerable groups. The objective of this paper is to analyze the differences between women living homeless born in Spain (non-immigrants) and those born abroad (immigrants). The study was carried out based on the data obtained from a sample of women living homeless in Madrid (Spain) ( $\mathrm{n}=136)$. The information was collected using a structured interview. The results show major similarities between immigrant and non-immigrant homeless women in terms of their basic socio-demographic characteristics (age, marital status, number of children), their state of health, satisfaction with their family and/or partner relationships, and feelings of loneliness or abandonment. Fewer immigrant women had their documentation in order, they received fewer financial benefits and their contact with their family of origin was more limited. However, the immigrant women became homeless at an older age and were subject to less chronic homelessness, their levels of consumption of alcohol and other psychoactive substances were lower, they had experienced fewer stressful life events, more of them had completed higher education, and more of them used mobile telephones and the Internet.
\end{abstract}

Keywords: Homeless; Women; Immigrants; Social exclusion; Poverty.

Public policy relevance. The study reveals the existence of differences between immigrant and non-immigrant homeless women in terms of education, sources of income, consumption of psychoactive substances, family networks, access to full citizenship, chronification in the homeless situation, stressful life events experienced or use of mobile telephony and the Internet. Data obtained can be useful for policy makers design programmes to support inmigrant women living homeless in the processes aimed at improving their situation. 


\section{Introduction}

People in homeless situation are one of the most obvious embodiments of the phenomenon of social exclusion (Panadero, Guillén \& Vázquez, 2015; Vázquez, Berrios, Bonilla \& Suarez, 2019a). Among people living homeless, women are a group who have different characteristics, needs and life trajectories from those of men (Vázquez \& Panadero, 2019), and they are considered a particularly vulnerable group (Arangua, Andersen \& Gelberg, 2005; Ryan et al., 2009), about which little research has been carried out in Spain. There have also been very few studies of foreign people living homeless in Spain, despite the fact that this population is considered particularly vulnerable (Navarro-Lashayas \& Eiroa-Orosa, 2017).

There were 4,572,807 immigrants in Spain in 2017 (amounting to 9.8\% of the country's population), of whom $38.9 \%$ came from the European Union (EU), $22.7 \%$ from Africa, $22.1 \%$ from South America, Central America and the Caribbean, 9.2\% from Asia, 5.7\% from other European countries that are not members of the EU, 1.3\% from North America and $0.1 \%$ from Oceania (INE, 2018). Various studies conducted with immigrants in western countries show increased levels of distress compared to age-matched native populations (Fazel, Wheeler, \& Danesh, 2005; Lindert, Ehrenstein, Priebe, Mielck, \& Brähler, 2009). Among other factors, this may be the result of the difficulties these groups have in gaining access to full citizenship, and the consequences that this entails (Brune, Eiroa-Orosa, Fischer-Ortman, \& Haasen, 2014). Immigrants also tend to have higher levels of exposure to violent situations than their nativeborn peers (Navarro-Lashayas \& Eiroa-Orosa, 2017), and Lam and Rosenheck (1998) point out that victimisation may be associated with alcohol abuse.

Meanwhile, various studies report that immigrants in homeless situation usually face additional difficulties compared to their native-born peers, such as more limited social networks, racism and problems with their legal status (Edgar, Doherty, \& Meert, 2004; Navarro-Lashayas \& Eiroa-Orosa, 2017). However, recent homeless immigrants have been observed to be in better health than their native-born age-matched counterparts (Chiu, Redelmeier, Tolomiczenko, Kiss, \& Hwang, 2009). There is very little scientific literature in Spain specifically regarding foreign people living homeless. Therefore, there are limited data available on the particular circumstances of this group, including origin and sociodemographic characteristics. In the study of homeless immigrants conducted in Bilbao (Spain) (NavarroLashayas and Eiroa-Orosa; 2017), the 107 interviewees were mainly male (97.2\% male, 2.8\% female), singles (83.3\%), relatively young (interviewees' mean age was 32) and frequent alcohol consumers $(40 \%)$. Despite having lived many years in Spain (a mean period of 5.5 years), the interviewees were mostly undocumented (76.7\%). This group of people came mainly from Africa (65\% from North Africa and 21.7\% from Sub-Saharan Africa) and, to a lesser extent, from Latin America (8.3\%); Eastern Europe (3.3\%) and Asia (1.7\%). Despite living in a homeless situation for long periods of time (they and had been homeless for a mean of 13 months) the time in this situation was inferior to their stay in Spain. This indicates that they became homeless after relatively long periods of time in Spain.

In Spain, homeless women account for $15 \%-20 \%$ of the total number of homeless people (Vázquez \& Panadero, 2019). Although various studies report that homeless women are usually younger than homeless men and more of them live with their children (Marsapt, 2000; North \& Smith, 1993), in Madrid there was no significant difference between homeless women and men in terms of their main socio-demographic characteristics (age, nationality, marital status, number of children, etc.) (Vázquez, Panadero, \& Pascual, 2019b). Homeless women tend to use shelters more often and spend the night in the street lesser often than men (Marsapt, 2000; North \& Smith, 1993). This tends to be related to women's greater vulnerability (Arangua et al., 2005; Ryan et al., 2009) and the increased risk that spending the night in the street entails 
for them. The perception of this greater vulnerability among women by the service providers seems to facilitate them being given priority access to care facilities (Vázquez et al., 2019b).

Various circumstances that affect homeless people in general (e.g. limited education, difficulty gaining access to the labour market, poor health, psychoactive substance abuse, poor social support, etc.) can be vulnerability factors that potentially have an impact on them becoming and remaining homeless (Roca, Panadero, Rodríguez, Martín, \& Vázquez, 2019), and affect homeless people differently depending on their gender and whether or not they are immigrants.

Various authors (Christensen \& Vinther, 2005; Marsapt, 2000; North \& Smith, 1993; Piliavin, Wright, \& Mare, 1996; Zlotnick, Robertson, \& Lahiff, 1999) have pointed out that periods of homelessness are longer for men than women, and Christensen and Vinther (2005) report that men experience considerably more episodes of homelessness than women. However, Vázquez et al. (2019b) observed that in Madrid there were no relevant differences according to gender for remaining homeless, and that the phenomenon of the "revolving door to homelessness" appeared to affect women to a greater extent. Many circumstances may lead individuals to suffer from repeated episodes of homelessness after gaining access to independent housing, although issues related to health, excessive alcohol consumption and experiencing stressful life events appear to be particularly influential (Aubry, Klodawsky, \& Coulombe, 2012; Caton et al., 2005; Dworsky, Napolitano, \& Courtney, 2013; Greenberg \& Rosenheck, 2009; Kim, Kertesz, Horton, Tibbetts, \& Samet, 2006; Muñoz, Vázquez, \& Vázquez, 2004; Parker, 2010; Roca et al., 2019).

Various studies have found that the educational level of homeless people is lower than that of the general population (e.g. Leonori et al., 2000; Muñoz et al., 2004) and they have extreme difficulty in accessing the labour market (e.g. Muñoz et al., 2004; Shaheen \& Rio, 2007; Vázquez et al., 2019b). Although women homeless tend to have a higher level of education than homeless men (North \& Smith, 1993), they have had more unstable and poorer quality jobs during their lives (e.g. O'Grady \& Gaetz, 2004, Okamoto, 2007), and face greater difficulties gaining access to the labour market and keeping their job (Vázquez et al., 2019b).

The health of people living homeless is considerably worse than that of the general population (e.g. Leonori et al., 2000; Muñoz et al., 2004) and homeless women were in poorer health, and suffered from more serious or chronic diseases than homeless men (Arangua et al., 2005; Wenzel et al., 2000), and had greater barriers to accessing medical care (Gelberg, Browner, Lejano, \& Arangua, 2004; Lewis, Andersen \& Gelberg, 2003) and higher levels of consumption of sedatives (Guillén, Marín-Martín, Panadero, \& Vázquez, 2019b). Chiu et al. (2009) point out that recent homeless immigrants are in better health than their native-born agematched counterparts. There are no significant differences according to gender between homeless women and homeless men in Madrid as regards disability (Vázquez et al., 2019b). Various studies show that compared to homeless men, homeless women present fewer problems resulting from excessive alcohol consumption (e.g. Christensen \& Vinther, 2005; Panadero, Vázquez \& Martín, 2017; Suarez, Berrios, Bonilla, \& Vázquez, 2018; North \& Smith, 1993; Vázquez et al., 2019a), although there are no relevant differences for excessive drug use according to gender (e.g. Arangua et al., 2005; Christensen \& Vinther, 2005; Robertson, Zlotnick, \& Westerfelt, 1997).

Most homeless people report feelings of loneliness or abandonment, with no relevant differences according to gender (Rokach, 2005). However, despite stereotypes to the contrary (Vázquez et al., 2017), Bates and Toro (1999) point out that most homeless people are in regular contact with their family, although they usually say they are dissatisfied with their relationship with their family. Meanwhile, Vázquez et al. (2019b) found that a large percentage of homeless 
women in Madrid had a partner, which has sometimes been interpreted as a means of obtaining protection in hostile environments (e.g. Ryan et al., 2009; Vázquez \& Panadero, 2019).

Although difficulties accessing and using ICTs (Information and Communication Technologies) do not seem to play a decisive role in people becoming and remaining homeless (Vázquez, Panadero, Martín \& Díaz-Pescador, 2015), problems related to access to these technologies can be a factor which acts as a barrier to their processes of social inclusion when combined with other circumstances. A common stereotype is that homeless people do not have access to ICTs, and that when they are able to access them, they lack the skills to use them properly (Eyrich-Garg, 2010). However, Vázquez et al. (2015) observed that homeless people in Madrid, especially those of foreign origin, had some access to ICTs, and particularly mobile phones. Eyrich-Garg (2010) points out that homeless people owned and used mobile phones to increase their sense of safety, responsibility (employment, personal business, and sobriety or "clean time"), and social connectedness.

The lack of research focusing on immigrant women living homeless in Spain has rendered this situation invisible, and has severely restricted the specific analysis of the distinctive characteristics and needs of women who are immigrants living homeless. This study examines the differences between women living homeless who came to Spain from other countries and those who were born in Spain. It focuses on different variables that enable an analysis of whether women who are immigrant living homeless have different circumstances and needs, which require different approaches to prevention and/or treatment for this specific subgroup.

\section{Method}

The research was conducted in Madrid (Spain) based on the data provided by homeless women $(n=136)$. The criteria for inclusion in the sample were being a woman, and meeting the criteria for belonging to one of the first three operational categories in the "European Typology on Homelessness and Housing Exclusion" (ETHOS): 1) People living rough, 2) People in emergency accommodation, and 3) People in accommodation for the homeless. All the participants were of legal age, and had spent the night before the interview in a shelter for the homeless, in the street or other places not initially designed for sleeping (abandoned buildings, basements...).

The women interviewed were recruited in shelters and drop-in centres for people living homeless, in the street and in public spaces. All the facilities in the "Network of care centres for people living homeless" in Madrid which worked with women were contacted to gain access to the participants. The shelters and drop-in centres provided places that ensured the interviewees' comfort and privacy when the interviews were conducted. Occasionally, if the women wished, an appointment was made to meet and interview them somewhere else (in a cafeteria, park, mall, etc.). For women living in the street, outreach teams provided the location and facilitated contact with the interviewees. After making contact, the interviewers introduced themselves, asked for their cooperation and made sure that they met the criteria for inclusion in the sample. The interviews with women in street scenarios were conducted in cafeterias, fast food restaurants, parks, malls, etc. Places that provided the interviewees with comfort and privacy were sought. Due to the relatively small number of homeless women who spent the night in shelters, in supervised accommodation, in the street or in public spaces, all the women who were contacted who met the criteria for inclusion in the sample were asked to participate in the study. 
The study was conducted out over twelve months, in compliance with the Internal Review Board of the Faculty of Psychology of the Complutense University of Madrid. The participants were asked for their informed consent after receiving an explanation of the purpose of the research and the treatment that the data would receive, and they were assured that their anonymity would be respected. In view of the results obtained in previous studies (Muñoz et al., 2004; Panadero, Martín, \& Vázquez, 2018), it was anticipated that a relatively high proportion of the interviewees could have a low level of education, and that the foreign homeless women in Madrid could potentially have difficulty understanding the Spanish language. As a result, a structured interview was used to gather information, which enabled us to circumvent the possible problems arising from the interviewees' difficulties with reading and/or understanding. The structured interview used was a version with a gender perspective of an instrument used in previous studies for people living homeless in Madrid (i.e Panadero et al., 2015, 2017, 2018; Vázquez et al., 2015, 2017, 2019b), which was adapted to the fact that the interviewees were women The structured interview collected information on 1,227 variables, and lasted between 45 and 80 minutes.

The interviews were conducted by four interviewers with experience in researches of similar characteristics (i.e. Panadero et al., 2018; Vázquez \& Panadero, 2016; Vázquez, Panadero \& Rivas, 2015; Vázquez, Suarez, Berríos \& Panadero, 2019c), carried out with people in social exclusion using very similar structured interviews. The interviewers spoke Spanish and English, and all the women interviewed spoke enough Spanish and / or English to complete the structured interview. The database was developed and processed using the SPSS statistical analysis and data management system. When making comparisons, the $\chi 2$ Chi square 2 statistic was used for nominal variables, and the Student $t$ test for independent samples was used for continuous variables.

\section{Results}

Of the 136 homeless women interviewed in Madrid, 59.6\% (81) were born in Spain and $40.4 \%$ (55) were born outside Spain: Forty percent (22) were born in Latin American countries (3 in Colombia, 3 in Ecuador, 2 in Cuba, 2 in Brazil, 2 in Venezuela, 2 in El Salvador, 2 in Paraguay, 2 in Uruguay, 1 in Bolivia, 1 in Chile, 1 in Argentina, and 1 in the Dominican Republic), 27.3\% (15) were born in European Union (EU) countries (8 in Romania, 3 in Portugal, 1 in Poland, 1 in Finland, 1 in France, and 1 in Lithuania), 21.8\% (12) were born in African countries (4 in Morocco, 4 in Nigeria, 1 in Cameroon, 1 in Cape Verde, 1 in Angola, and 1 in Ethiopia), 7.3\% (4) were born in European countries that are not members of the EU ( 2 in Ukraine, 1 in Bosnia-Herzegovina, and 1 in Russia) and 3.6\% (2) were born in the United States of America. 
Table 1. Socio-demographic characteristics and place of overnight stay for immigrant and nonimmigrant women living homeless in Madrid.

\begin{tabular}{lccc}
\hline & $\begin{array}{c}\text { Women non- } \\
\text { immigrants } \\
(\mathbf{n}=\mathbf{8 1})\end{array}$ & $\begin{array}{c}\text { Women } \\
\text { immigrants } \\
(\mathbf{n}=\mathbf{5 5})\end{array}$ & $\mathbf{t} / \chi^{\mathbf{2}}$ \\
\hline Age (M years, SD) & $45.5(10.47)$ & $45.6(12.86)$ & 2.865 \\
\hline Marital status & & & 4.413 \\
$\quad$ Single & $60.5 \%(49)$ & $60.0 \%(33)$ & \\
$\quad$ Married & $4.9 \%(4)$ & $7.3 \%(4)$ & \\
$\quad$ Legally separated or divorced & $23.5 \%(19)$ & $14.5 \%(8)$ & \\
$\quad$ Separated de facto without legal & $8.6 \%(7)$ & $9.1 \%(5)$ & \\
$\quad$ procedures & & & \\
$\quad$ Widow & $2.5 \%(2)$ & $9.1 \%(5)$ & \\
\hline Has children & $63.0 \%(51)$ & $58.2 \%(32)$ & 0.315 \\
$\quad$ Number of children (M children, SD) & $1.3(1.31)$ & $1.4(1.70)$ & 2.982 \\
\hline Nationality & $100 \%(81)$ & $14.5 \%(8)$ & $105.772 * * *$ \\
$\quad$ Spanish & $0 \%$ & $74.5 \%(41)$ & \\
$\quad$ Foreign & $0 \%$ & $10.9 \%(6)$ & \\
$\quad$ Double nationality (Spanish and other) & $97.5 \%(79)$ & $67.9 \%(36)$ & $23.077 * * *$ \\
\hline Has documentation in order & & & \\
\hline In the past month she has slept... & $11.3 \%(9)$ & $12.7 \%(7)$ & 0.068 \\
$\quad$ In the street & $5.0 \%(4)$ & $9.1 \%(5)$ & 0.877 \\
$\quad$ In an unsuitable place & $76.5 \%(62)$ & $90.0 \%(50)$ & $4.652 *$ \\
$\quad$ In a shelter for homeless people & &
\end{tabular}

$* \mathrm{p} \leq .05 ; * * \mathrm{p} \leq .01 ; * * \mathrm{p} \leq .001$.

As shown in Table 1, the women in homeless situation interviewed had a mean age of 45.5 years old, and were mostly single or separated/divorced. More than half of them had children, with a mean of around 1.5 children per woman. No statistically significant differences were observed between the immigrants and non-immigrants interviewed in terms of age, marital status, having children or the average number of children per woman. Differences in the interviewees' nationalities were observed, with $100 \%$ of those born in Spain and $25.4 \%$ of those born abroad having Spanish nationality. Two interviewees born in Spain and a third of the immigrant women did not have their documentation in order: Three were from EU countries (Romania and Portugal), 4 were from Latin America (Argentina, Brazil and Paraguay), 2 were from Morocco, 4 were from Sub-Saharan Africa (Nigeria and Cape Verde), 2 were from European countries which are not members of the EU (Bosnia-Herzegovina and Russia) and 1 was from the USA.

Furthermore, as can be seen from Table 1, no statistically significant differences were observed between the immigrant and non-immigrant interviewees in terms of having slept in the street or in a place not suitable for overnight stays in the month prior to the interview, although a larger percentage of the immigrants had slept in shelters for the homeless. 
Table 2. Time spent homeless, number of episodes of homelessness and age when they became homeless for the first time for immigrant and non-immigrant women living homeless in Madrid

\begin{tabular}{lccc}
\hline & $\begin{array}{c}\text { Women non- } \\
\text { immigrants } \\
(\mathbf{n}=\mathbf{8 1})\end{array}$ & $\begin{array}{c}\text { Women } \\
\text { immigrants } \\
(\mathbf{n}=\mathbf{5 5})\end{array}$ & $\mathbf{t}$ / $\chi^{\mathbf{2}}$ \\
\hline Number of times homeless during her life & & & 1.586 \\
$\quad$ Once & $37.7 \%(29)$ & $46.2 \%(24)$ & \\
$\quad 1$ to 5 times & $27.3 \%(21)$ & $28.8 \%(15)$ & \\
$\quad$ More than 5 times & $35.1 \%(27)$ & $25.0 \%(13)$ & \\
\hline Age when she became homeless (M years, & $34.32(13.815)$ & $40.11(14.895)$ & $0.155^{*}$ \\
SD) & & & \\
\hline Time spent homeless (M month, SD) & $95.8(103.55)$ & $45.7(58.48)$ & $14.430^{* * *}$ \\
\hline
\end{tabular}

$* \mathrm{p} \leq .05 ; * * \mathrm{p} \leq .01 ; * * \mathrm{p} \leq .001$.

As can be seen in Table 2, there are no statistically significant differences between the immigrant and non-immigrant interviewees in terms of the number of times they had been homeless during their lives. However, the immigrant interviewees had become homeless for the first time at an older age than the non-immigrants, and had spent half the time homeless (3.8 years vs. 8.0 years).

Table 3. Academic background, employment activities and income of immigrant and nonimmigrant women living homeless in Madrid.

\begin{tabular}{lccc}
\hline & $\begin{array}{c}\text { Women non- } \\
\text { immigrants } \\
\text { (n=81) }\end{array}$ & $\begin{array}{c}\text { Women } \\
\text { immigrants } \\
\text { (n=55) }\end{array}$ & $\chi^{\mathbf{2}}$ \\
\hline Level of education & $7.4 \%(6)$ & $10.9 \%(6)$ & $11.757^{*}$ \\
No education & $14.8 \%(12)$ & $9.1 \%(5)$ & \\
Incomplete primary education & $40.7 \%(33)$ & $21.8 \%(12)$ & \\
Primary education (up to 14 years old) & $18.5 \%(15)$ & $20.0 \%(11)$ & \\
Secondary (up to 18 years old) & $3.7 \%(3)$ & $16.4 \%(9)$ & \\
Higher non-university education & $14.8 \%(12)$ & $21.8 \%(12)$ & \\
Higher university studies & & & \\
Source of income during the previous month & $22.2 \%(18)$ & $16.4 \%(9)$ & 0.707 \\
Begging & $23.5 \%(19)$ & $9.1 \%(5)$ & $4.652^{*}$ \\
Basic guaranteed income & $7.4 \%(6)$ & $12.7 \%(7)$ & 1.072 \\
Wages & $6.4 \%(5)$ & $1.8 \%(1)$ & 1.579 \\
Criminal activities & $2.5 \%(2)$ & $3.6 \%(2)$ & 0.137 \\
Prostitution & $16.0 \%(13)$ & $5.5 \%(3)$ & $3.542 *$ \\
Non-contributory pension & $1.2 \%(1)$ & $0 \%(0)$ & 0.684 \\
Unemployment benefit & $2.5 \%(2)$ & $1.8 \%(1)$ & 0.064 \\
Retirement pension & $4.9 \%(4)$ & $3.6 \%(2)$ & 0.132 \\
Disability pension & $2.5 \%(2)$ & $1.8 \%(1)$ & 0.070 \\
Marginal activity & $1.2 \%(1)$ & $0 \%(0)$ & 0.684 \\
Widowhood pension & $6.2 \%(5)$ & $0 \%(0)$ & 3.525 \\
Other benefits & \multicolumn{3}{c}{} \\
\hline
\end{tabular}

$* \mathrm{p} \leq .05 ; * * \mathrm{p} \leq .01 ; * * * \mathrm{p} \leq .001$. 
As shown in Table 3, there are differences in the educational level of the immigrant and non-immigrant interviewees. A smaller percentage of the women interviewed had completed primary education, and among the immigrants, a larger percentage of the women had completed higher education. In the month prior to the interview, the interviewees' primary source of income was begging, with no statistically significant differences between the immigrants and non-immigrants. Fewer immigrants received the basic guaranteed income (9\% vs. 23\%) and a non-contributory pension ( $5 \%$ vs. $16 \%$ ).

In the month prior to the interviews, the non-immigrant homeless women had received a mean of 294.4 Euros ( $\mathrm{SD}=314.41)$ and the immigrant women 124.0 Euros ( $\mathrm{SD}=213.17)$ from all the sources of income listed in Table $3(t=2665, p=0.000)$.

Table 4. Health and consumption of psychoactive substances among homeless immigrant and non-immigrant women in Madrid.

\begin{tabular}{|c|c|c|c|}
\hline & $\begin{array}{c}\text { Women non- } \\
\text { immigrants } \\
(n=81) \\
\end{array}$ & $\begin{array}{c}\text { Women } \\
\text { immigrants } \\
(\mathrm{n}=55)\end{array}$ & $\mathbf{t} / \chi^{2(1)}$ \\
\hline $\begin{array}{l}\text { Has been diagnosed with a serious or chronic } \\
\text { illness by a doctor }\end{array}$ & $55.6 \%(45)$ & $49.1 \%(26)$ & 0.543 \\
\hline Has visited the doctor in the last year & $90.0 \%(72)$ & $92.3 \%(48)$ & 0.203 \\
\hline Has visited the emergency ward in the last year & $61.3 \%(49)$ & $52.8 \%(28)$ & 0.927 \\
\hline $\begin{array}{l}\text { Has a disability or handicap (physical, sensory, } \\
\text { mental) }\end{array}$ & $41.0 \%(32)$ & $30.2 \%(16)$ & 1.596 \\
\hline Has an officially recognised disability ${ }^{(1)}$ & $75.8 \%(25)$ & $56.3 \%(9)$ & 1.930 \\
\hline \multicolumn{4}{|l|}{ Has used sedatives } \\
\hline At some point in her life & $64.2 \%(52)$ & $49.1 \%(27)$ & 3.071 \\
\hline In the last 6 months & $60.5 \%(49)$ & $36.4 \%(20)$ & $7.631 * *$ \\
\hline \multicolumn{4}{|l|}{ In the last month... } \\
\hline $\begin{array}{l}\text { Amount of alcohol (glasses, etc.) usually } \\
\text { consumed in a single day (M glasses, SD) }\end{array}$ & $1.9(3.60)$ & $0.9(2.52)$ & 4.945 \\
\hline $\begin{array}{l}\text { Number of days when she has consumed alcohol } \\
\text { (M days, SD) }\end{array}$ & $4.5(9.20)$ & $3.4(9.16)$ & 0.432 \\
\hline $\begin{array}{l}\text { Number of days when she has had at least } 4 \\
\text { drinks (M days, SD) }\end{array}$ & $1.5(5.97)$ & $0(--)$ & $2.191 *$ \\
\hline \multicolumn{4}{|l|}{ Cocaine use } \\
\hline At some point in her life & $53.1 \%(43)$ & $25.5 \%(14)$ & $10.273 * * *$ \\
\hline In the last 6 months & $14.8 \%(12)$ & $7.3 \%(4)$ & 1.795 \\
\hline \multicolumn{4}{|l|}{ Heroin use } \\
\hline At some point in her life & $35.8 \%(29)$ & $12.7 \%(7)$ & $8.961 * *$ \\
\hline In the last 6 months & $9.9 \%(8)$ & $1.8 \%(1)$ & 3.442 \\
\hline \multicolumn{4}{|l|}{ Methadone use } \\
\hline At some point in her life & $25.9 \%(29)$ & $12.7 \%(7)$ & $3.490^{*}$ \\
\hline In the last 6 months & $16.0 \%(13)$ & $10.9 \%(6)$ & 0.720 \\
\hline \multicolumn{4}{|l|}{ Cannabis use } \\
\hline At some point in her life & $55.6 \%(45)$ & $18.2 \%(10)$ & $18.996 * * *$ \\
\hline In the last 6 months & $18.5 \%(15)$ & $0 \%(0)$ & $11.448 * * *$ \\
\hline \multicolumn{4}{|l|}{$\begin{array}{l}\text { At some point in her life she has received some } \\
\text { kind of specific treatment for... }\end{array}$} \\
\hline Drug use & $33.3 \%(27)$ & $12.7 \%(7)$ & $7.418 * *$ \\
\hline Alcohol consumption & $16.0 \%(13)$ & $7.3 \%(4)$ & 2.307 \\
\hline
\end{tabular}

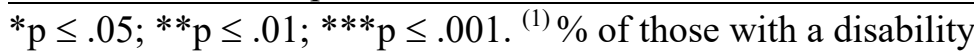


As shown in Table 4, a very large percentage of the interviewees had been diagnosed with a serious or chronic illness, with disability problems, which were often officially recognised, and had made frequent visits to general and emergency healthcare services. However, there were no statistically significant differences between the immigrants and nonimmigrants.

A large percentage of the interviewees had used sedatives, although fewer of the immigrants had used sedatives in the six months prior to the interview. The interviewees reported a relatively low level of alcohol consumption, with few differences between the immigrants and non-immigrants. However, unlike the non-immigrants, the immigrants interviewed reported not having consumed more than four alcoholic drinks (glasses, etc.) in a day during the previous month. Cocaine and cannabis were the drugs most extensively consumed by homeless women in Madrid at some point in their life, as well as methadone in the last 6 months. The immigrants interviewed reported a lower level of consumption during their lives of all the substances listed in Table 4 (cocaine, heroin, methadone and cannabis), and cannabis in the 6 months prior to the interview. None of the immigrants said they had consumed this substance in this period. Fewer homeless immigrant women had received treatment for drug use during their lives than the non-immigrants, although no statistically significant differences were observed between the immigrants and non-immigrants as regards having received some type of treatment for problems due to from drug use.

Table 5. Social support among homeless immigrant and non-immigrant women in Madrid.

\begin{tabular}{|c|c|c|c|}
\hline & $\begin{array}{c}\text { Women non- } \\
\text { immigrants } \\
(n=81)\end{array}$ & $\begin{array}{c}\text { Women } \\
\text { immigrants } \\
(n=55)\end{array}$ & $\chi^{2}$ \\
\hline Has a family & $90.1 \%(73)$ & $83.6 \%(46)$ & 1.260 \\
\hline Frequency of contact with her family & & & $19.743 * * *$ \\
\hline Never & $42.5 \%(31)$ & $82.6 \%(38)$ & \\
\hline Monthly or less than once a month & $28.8 \%(21)$ & $10.9 \%(5)$ & \\
\hline At least once a week & $28.7 \%(21)$ & $6.5 \%(3)$ & \\
\hline $\begin{array}{l}\text { Level of satisfaction with her relationship with } \\
\text { her family }\end{array}$ & & & 2.968 \\
\hline Not at all or not very satisfied & $52.1 \%(38)$ & $56.5 \%(26)$ & \\
\hline Quite or very satisfied & $47.9 \%(35)$ & $43.5 \%(20)$ & \\
\hline Has a partner & $38.3 \%(31)$ & $41.8 \%(23)$ & \\
\hline Frequency of contact with her partner & & & 4.125 \\
\hline Never or less than once a month & $3.2 \%(1)$ & $13.0 \%(3)$ & \\
\hline Weekly or monthly & $19.4 \%(6)$ & $21.7 \%(5)$ & \\
\hline Almost every day & $77.4 \%(24)$ & $65.2 \%(15)$ & \\
\hline $\begin{array}{l}\text { Satisfaction with the relationship with her } \\
\text { partner }\end{array}$ & & & 2.674 \\
\hline Not at all or not very satisfied & $10.0 \%(3)$ & $8.6 \%(2)$ & \\
\hline Quite or very satisfied & $90.0 \%(27)$ & $91.3 \%(21)$ & \\
\hline The extent to which she fells alone or abandoned & & & 2.280 \\
\hline Not at all & $34.2 \%(27)$ & $25.0 \%(13)$ & \\
\hline Not much & $16.5 \%(13)$ & $21.2 \%(11)$ & \\
\hline Quite a lot & $21.5 \%(17)$ & $17.3 \%(9)$ & \\
\hline A lot & $27.8 \%(22)$ & $36.5 \%(19)$ & \\
\hline
\end{tabular}

$* \mathrm{p} \leq .05 ; * * \mathrm{p} \leq .01 ; * * \mathrm{p} \leq .001$. 
As shown in Table 5, the vast majority of the interviewees had a family, although only half reported having a satisfactory relationship with their family, and around $40 \%$ had a partner, and said they were very satisfied with their relationship. No statistically significant differences were observed between immigrants and non-immigrants regarding these issues. The only difference observed between the two groups is related to the frequency of contact they have with their family, which is much lower among the immigrant interviewees. Forty-nine point three percent of the non-immigrants and $53.8 \%$ of the immigrants said they felt quite or very lonely or abandoned, with no statistically significant differences between the two groups.

Table 6. Experience of stressful life events among immigrant and non-immigrant women living homeless in Madrid.

\begin{tabular}{|c|c|c|c|}
\hline & $\begin{array}{c}\text { Women non- } \\
\text { immigrants } \\
(n=81)\end{array}$ & $\begin{array}{c}\text { Women } \\
\text { immigrants } \\
(n=55)\end{array}$ & $\chi^{2}$ \\
\hline \multicolumn{4}{|l|}{$\begin{array}{l}\text { Stressful life events experienced before } 18 \text { years } \\
\text { of age }\end{array}$} \\
\hline A parent had problems with alcohol & $37.0 \%(30)$ & $20.4 \%(11)$ & $4.256^{*}$ \\
\hline Serious fights and arguments between her parents & $45.7 \%(37)$ & $27.8 \%(15)$ & $4.384^{*}$ \\
\hline $\begin{array}{l}\text { Serious conflicts between her and someone in her } \\
\text { family }\end{array}$ & $40.0 \%(32)$ & $20.8 \%(11)$ & $5.397 *$ \\
\hline She was thrown out of home & $24.7 \% 820)$ & $9.4 \%(5)$ & $4.914^{*}$ \\
\hline She ran away from home & $40.7 \%(33)$ & $24.5 \%(13)$ & $3.735^{*}$ \\
\hline She dropped out of school & $39.5 \%(32)$ & $22.6 \%(12)$ & $4.132 *$ \\
\hline She was expelled from school & $14.8 \%(12)$ & $3.8 \%(2)$ & $4.174^{*}$ \\
\hline She suffered from abuse & $48.1 \%(39)$ & $32.1 \%(17)$ & $3.402 *$ \\
\hline She suffered from sexual abuse & $38.3 \%(31)$ & $18.9 \%(10)$ & $5.680^{*}$ \\
\hline \multicolumn{4}{|l|}{$\begin{array}{l}\text { Stressful life events experienced throughout her } \\
\text { life }\end{array}$} \\
\hline Abused drugs at some point in her life & $48.1 \%(39)$ & $22.6 \%(12)$ & $8.841^{* *}$ \\
\hline She has been in prison & $32.1 \% 26)$ & $13.2 \%(7)$ & $6.160 * *$ \\
\hline She lost her home due to eviction & $28.4 \%(23)$ & $7.5 \%(4)$ & $8.655 * *$ \\
\hline $\begin{array}{l}\text { She has suffered from abuse by her spouse or } \\
\text { partner }\end{array}$ & $72.8 \%(59)$ & $34.0 \%(18)$ & $19.810 * * *$ \\
\hline $\begin{array}{l}\text { She has suffered from physical violence (over } 18 \\
\text { years old) }\end{array}$ & $60.5 \%(49)$ & $42.3 \%(22)$ & $4.209^{*}$ \\
\hline She has been reported to the police & $44.4 \%(36)$ & $22.6 \%(12)$ & $6.625 * *$ \\
\hline She has been arrested or detained for a crime & $46.9 \%(38)$ & $28.3 \%(15)$ & $4.642 *$ \\
\hline She has been convicted of a crime & $34.6 \%(28)$ & $13.2 \%(17)$ & $7.757 * *$ \\
\hline
\end{tabular}
${ }^{*} \mathrm{p} \leq .05 ;{ }^{* *} \mathrm{p} \leq .01 ; * * * \mathrm{p} \leq .001$. 
Table 6 shows the differences between the immigrant and non-immigrant interviewees in terms of suffering from certain stressful life events, both during childhood and adolescence and throughout their lives. The percentage of women who had suffered from severe stressful life events was very high in both groups, although during childhood and adolescence, the nonimmigrants suffered from more problems in their family environment (one of the parents having alcohol problems, serious fights and arguments between parents, serious arguments with family members, ejection from the home or escaping from the place where she lived), at school (dropping out of school, being expelled from school), and from sexual abuse. Furthermore, during their lives the non-immigrants had suffered to a greater extent from problems with justice (complaints, arrests, legal sentences, imprisonment), violence (intimate partner violence), excessive drug use and loss of their home.

Table 7. Use of new technologies by immigrant and non-immigrant homeless women in Madrid.

\begin{tabular}{lccc}
\hline & $\begin{array}{c}\text { Women non- } \\
\text { immigrants } \\
(\mathbf{n = 8 1 )}\end{array}$ & $\begin{array}{c}\text { Women } \\
\text { immigrants } \\
(\mathbf{n = 5 5 )}\end{array}$ & $\chi^{\mathbf{2}}$ \\
\hline Owns a mobile phone & $70.5 \%(55)$ & $84.9 \%(45)$ & $3.619^{*}$ \\
Uses a computer & $44.9 \%(35)$ & $60.4 \%(32)$ & 3.036 \\
Uses the Internet & $43.6 \%(34)$ & $60.4 \%(32)$ & $3.558^{*}$ \\
Has an e-mail address & $46.2 \%(36)$ & $60.4 \%(32)$ & 2.557 \\
Uses some type of social networks & $32.5 \%(25)$ & $35.8 \%(19)$ & 0.160 \\
\hline
\end{tabular}

$* \mathrm{p} \leq .05 ; * * \mathrm{p} \leq .01 ; * * * \mathrm{p} \leq .001$

As can be seen from Table 7, an equal or larger percentage of the immigrant interviewees used communication technologies as the non-immigrants. While the use of social networks, computers and email was similar in the two groups, the use of the Internet and mobile phone availability was greater among the immigrants.

\section{Discussion}

The results show major similarities between immigrant and non-immigrant homeless women in terms of their age, marital status, number of children, health, family satisfaction or loneliness. Immigrant homeless women are more vulnerable than non-immigrants in some respects: fewer immigrant women had their documentation in order, they received fewer financial benefits and their contact with their family was more limited. Nevertheless, it is observed that immigrant women living homeless show, in some aspects, greater strengths than non-immigrants: immigrant women became homeless at an older age and were subject to less time homelessness, their levels of consumption of substances were lower, they had experienced fewer stressful life events, more of them had completed higher education, and more of them used information and communications technologies.

Forty percent of the homeless women interviewed in Madrid were of foreign origin mainly from countries in the European Union (EU), Latin America and Africa, which are the places of origin of most of Spain's immigrant population (INE, 2018). It should be noted that immigrants from the EU have a legally equal standing to Spaniards in terms of rights (i.e. employment, health, social, etc.), which in principle should not affect their ability to access social benefits, healthcare or legal employment. People who migrate to Spain from Latin America have important linguistic and cultural advantages when adapting to life in Spain, given the close historical and cultural relationship between Spain and the Latin American countries. 
However, the major linguistic and cultural differences between Spain and African countries means that migrants from Africa suffer from discrimination to a greater extent, and may find it more difficult to legalise their situation and gain access to social, health and employment benefits. One in four of the women who had been born abroad interviewed had Spanish nationality, meaning that in principle, they had the same rights (i.e. employment, health, access to social benefits, etc.) as the women born in Spain. The origin of the homeless women interviewed in Madrid bore very little relationship to the origin of the homeless immigrants (mainly males) interviewed in Bilbao (Spain) by Navarro-Lashayas and Eiroa-Orosa (2017), $87 \%$ of whom were from Africa (65\% from North Africa and $22 \%$ from Sub-Saharan Africa), while only a small percentage came from Latin America (8.3\%), Eastern Europe (3.3\%) or Asia $(1.7 \%)$.

The homeless immigrant and non-immigrant women interviewed in Madrid did not differ in many of their primary socio-demographic characteristics (age, marital status, number of children, etc.), and as such the differences between them cannot be attributed to these circumstances. Various authors (Marsapt, 2000; North \& Smith, 1993; Vázquez et al., 2019b) point out that homeless women tend to use shelters to a greater extent and to spend less time on the street, given the greater risk involved in spending the night in the street (Arangua et al., 2005; Ryan et al., 2009). More of the immigrant homeless women interviewed in Madrid had slept in shelters than the non-immigrants (90\% vs. $76 \%$ in the last month). This is perhaps due to their greater sense of vulnerability, weaker social networks and greater difficulties in gaining access to other specialised accommodation facilities (i.e. residences for the elderly, accommodation for women victims of gender violence, sheltered housing, etc.).

According to the scientific literature, homeless people have little social support (e.g. Muñoz et al., 2004; Panadero, Guillén, \& Vázquez, 2015; Nyamathi, Leake, Keenan, \& Gelberg, 2000). A large majority of both immigrant and non-immigrant homeless women in Madrid reported having a family, as observed by Bates and Toro (1999). Nevertheless, only half of the interviewees said they had a satisfactory relationship with their family, and contact with their family was very infrequent among the immigrants in particular. Meanwhile, around $40 \%$ of the interviewees reported having a partner, and although homeless women's relationships have tended to be interpreted as a means of obtaining protection in dangerous and hostile environments (e.g. Ryan et al., 2009; Vázquez et al., 2019b), a much larger percentage of the interviewees in Madrid were very satisfied with their relationship than among the men in the city (Vázquez et al., 2019b), with no relevant differences between immigrants and nonimmigrants. Having a partner can be an important source of social support among the interviewees. Although various authors (Edgar, Doherty, \& Meert, 2004; Navarro-Lashayas \& Eiroa-Orosa, 2017) point out that immigrant homeless people suffer more than their nativeborn peers from situations such as a lack of community relationships and less stable social networks, there are hardly any differences in the availability of social networks for migrant and non-immigrant women in Madrid. In general, homeless people tend to report feelings of loneliness or abandonment, without any relevant differences in terms of gender (Rokach, 2005), and accordingly, it is not surprising that half of the women interviewed reported feeling lonely or abandoned, with no differences between the immigrants and non-immigrants.

The immigrants interviewed have a higher level of education than the non-immigrants, especially in terms of having completed university studies ( $22 \%$ vs. $15 \%)$. Although the educational level of homeless people tends to be lower than that of the general population (Leonori et al., 2000), the educational level of homeless women tends to be higher than that of homeless men (North \& Smith, 1993; Vázquez et al., 2019b). In Madrid, more immigrant homeless women report having completed university education, which nevertheless does not appear to protect them from becoming homeless, or facilitate their access to the labour market. 
Various studies show that access to the labour market for homeless people is considerably difficult (e.g. Panadero et al., 2018; Shaheen \& Rio, 2007), and that compared to men in the same situation, homeless women have had to face greater difficulties gaining access to the labour market and keeping their job (Vázquez et al., 2019b), and have had more unstable and poorer quality jobs during their lives (O'Grady \& Gaetz, 2004, Okamoto, 2007). The higher educational level of the immigrant women does not seem to provide them with access to employment, although their main source of income after begging was some sort of employment, which was the source of income of 13\% of immigrant women in Madrid. The income levels of the immigrants interviewed were much lower than those of the non-immigrants (124 Euros vs. 295 Euros on average), and the immigrants had greater difficulties accessing social benefits (i.e. basic guaranteed income, non-contributory pension, etc.), which lowers their level of protection against becoming homeless and may imply a handicap in their social inclusion processes.

One third of the immigrants interviewed did not have their documentation in order, although this percentage is much lower than the percentage reported by Navarro-Lashayas and Eiroa-Orosa (2017) in Bilbao, where $76.7 \%$ of the homeless immigrants were undocumented. In comparative terms, fewer homeless immigrant women did not have their documentation in order, and of the 16 immigrants who reported not having their documentation in order, 3 came from EU member countries (Romania and Portugal), meaning that they should not have any problems when legalising their situation in Spain. The other 13 undocumented women (4 were born in Latin America (Argentina, Brazil and Paraguay), 6 in Africa (Morocco, Nigeria and Cape Verde), 2 in European countries which are not members of the EU (Bosnia and Russia) and 1 in the USA), would presumably find more difficult to legalise their situation. In the opinion of Brune et al. (2014), the difficulties faced by migrants in gaining access to full citizenship and the difficulties that this entails is one of the most important sources of psychosocial distress. Not having documentation in order hinders the individual's access to the labour market, and may also have a negative impact on access to social benefits, access to the healthcare system and access to and maintenance of housing. It also leads anxiety about the possibility of being required to provide identification by the police, and may be a factor in vulnerability to prostitution networks or potential extortionists. In addition to a potential source of stress in itself, not having documentation in order therefore makes everyday life difficult, and is a negative factor in social inclusion processes.

The immigrants interviewed had become homeless for the first time at an older age than the non-immigrants (40 years vs. 34 years) and had remained homeless for half the length of time (3.8 years vs. 8.0 years), although the "revolving door" effect was similar among the immigrants and non-immigrants. Accordingly, the migrants had a lower level of chronification, which in principle could be considered as a positive factor in their social inclusion processes. Many circumstances may lead individuals to suffer from chronic homelessness, although issues related to health, excessive alcohol consumption and experiencing stressful life events appear to be particularly influential (Aubry et al., 2012; Caton et al., 2005; Dworsky et al, 2013; Greenberg \& Rosenheck, 2009; Kim et al., 2006; Muñoz et al., 2004; Parker, 2010; Roca et al., 2019). Immigrant women living homeless had lower levels of consumption of alcohol and psychoactive substances, and they had suffered from fewer stressful life events. These circumstances could help to explain that homeless immigrant women spent less time in a homeless situation than non-immigrants.

The health of homeless people is significantly worse than that of the general population (e.g. Leonori et al., 2000; Muñoz et al., 2004; Guillén et al., in press), and the health of homeless women is particularly poor (Arangua et al., 2005; Gelberg, Browner, Lejano, \& Arangua, 2004; Lewis, Andersen \& Gelberg, 2003, Vázquez et al., 2019b; Wenzel et al., 2000). The women 
interviewed in Madrid were in particularly poor health, with important rates of disability and multiple serious or chronic illnesses, as well as many visits to healthcare services (both general and emergency), although there are no significant differences between the immigrant and nonimmigrant women in this respect. However, the level of sedative consumption was lower among the immigrants, which could be related to a relatively better state of health (Chiu et al., 2009; Guillén et al., in press).

Various studies point out that homeless women present fewer problems arising from excessive alcohol consumption than homeless men (e.g. Christensen \& Vinther, 2005; Panadero, Vázquez \& Martín, 2017; Suarez et al., 2018; North \& Smith, 1993; Vázquez et al., 2019a; Vázquez et al., 2019b), although there are no relevant differences in terms of drug use according to gender (e.g. Arangua et al., 2005; Christensen \& Vinther, 2005; Robertson, Zlotnick, \& Westerfelt, 1997; Vázquez et al., 2019b). The immigrant women in this study reported very low levels of alcohol and drug use, which were much lower than those of the nonimmigrant homeless women. This could be a positive factor in their processes of social inclusion.

The homeless women interviewed in Madrid suffered from multiple and serious stressful life events both in their childhood and adolescence and throughout their lives, which was consistent with the findings of various studies (e.g. Panadero, Martín, \& Vázquez, 2018; Vázquez et al, 2019c; Zugazaga, 2004). The immigrant interviewees had suffered from fewer stressful life events than the non-immigrants, during both childhood and adolescence (problems in the family environment, abuse, sexual abuse, school problems, etc.) and throughout their lives (problems with the justice system, violence, substance abuse, eviction, etc.), in contrast to the findings of various studies, which indicate that immigrants might have higher levels of previous exposure to violence and suffer from greater difficulties (Brune et al., 2014; Edgar, Doherty, \& Meert, 2004; Navarro-Lashayas \& Eiroa-Orosa, 2017).

According to various authors (Eyrich-Garg, 2010; Thomas \& Wyatt, 2000; Vázquez et al., 2015), use of ICTs (Information and Communication Technologies) is a major aspect of the knowledge society in terms of individuals' inclusion/exclusion from employment and society, especially among the most disadvantaged groups. The homeless women interviewed in Madrid use ICTs to a much lesser extent than the general population, which may have a negative impact in different contexts: employment, training, relations and leisure. Among the interviewees, an equal percentage of the immigrants were observed to use ICTs (computer, email, etc.) or a higher percentage (mobile phone, Internet, etc.) as those born in Spain. This can be attributed to aspects such as the migrants' higher educational level, their need to maintain contact with relatives and friends living in other countries, longer stays in shelters with access to computers and $\mathrm{Wi}-\mathrm{Fi}$, their increased ability to possess telephones due to living in shelters, etc. (Vázquez et al., 2015). As Bure (2005) points out, homeless people who own and use mobile phones have to deal with problems in order to use them (e.g. a lack of money to purchase them and keep them operational, thefts, losses, access to energy for charging, access to Wi-Fi, etc.). However, providing access to mobile telephony for homeless people can have a positive impact on their social inclusion processes, by facilitating their maintenance of social networks, their search for employment and housing, and access to the Internet. In addition, as Eyrich-Garg (2010) points out, mobile phones could be used to disseminate information to homeless people living in the street, to improve their communication with services and to facilitate their access to prevention, intervention and monitoring programmes. 


\section{Limitations and conclusions}

The limitations of this study include the fact that the criteria for sample inclusion in the research were restrictive (assignment to ETHOS operational categories 1, 2 and 3), and there was no randomised or stratified selection of the women interviewed. Accordingly, it is impossible to guarantee the representativeness of the sample, despite the fact that the women interviewed account for a significantly large percentage of the total number of women living homeless in Madrid. It should also be noted that the study is limited to Madrid, Spain, which means that it is difficult to generalise its results to other contexts. Furthermore, this is a crosssectional study design, and caution must therefore be exercised when trying to establish causal relationships.

However, despite the study's limitations, the results obtained indicate that the homeless immigrant women in Madrid presented some factors of special vulnerability, although they had major strengths. The immigrants and non-immigrants interviewed had similar sociodemographic characteristics (age, marital status, number of children, etc.) and there was very little difference in terms of sleeping in the street, the number of times they had been homeless, suffering from disability and serious and chronic illnesses, using health services, having a family and a partner, or feeling lonely or abandoned. However, although the immigrants had weaker family networks and greater difficulties in gaining access to full citizenship (e.g. having their documentation in order, accessing the basic guaranteed income or non-contributory pensions, etc.) in comparison with the non-immigrants, the immigrant interviewees were found to have become homeless at more advanced ages, they spent less time in a homeless situation, they had lower levels of consumption of alcohol and psychoactive substances, they had suffered from fewer stressful life events, they had higher levels of education and they used mobile telephony and the Internet to a greater extent. Finally, we hope that the information provided may be useful for enhancing the knowledge of homeless immigrant women, which is an understudied group, while at the same time enabling the development of public policies and care resources adapted to these women's characteristics and needs.

\section{References}

Arangua, L., Andersen, R., \& Gelberg, L. (2005). The health circumstances of homeless women in the United States. International Journal of Mental Health, 34(2), 62-92.

Aubry, T., Klodawsky, F., \& Coulombe, D. (2012). Comparing the housing trajectories of different classes within a diverse homeless population. American Journal of Community Psychology, 49(1-2), 142-155. DOI: doi.org/10.1007/s10464-011-9444-z.

Bates, D., \& Toro, P. (1999). Developing measures to assess social support among homeless and poor people. Journal of Community Psychology, 27, 137-156. DOI: doi.org/10.1002/(SICI)1520-6629(199903)27:2<137::AID-JCOP3>3.0.CO;2-B

Brune, M., Eiroa-Orosa, F. J., Fischer-Ortman, J., \& Haasen, C. (2014). Effectiveness of psychotherapy for traumatized refugees without a secure residency status. International Journal of Migration, Health and Social Care, 10, 52-59. http://dx.doi.org/10.1108/IJMHSC-07-2013-0022.

Bure, C. (2005). Digital inclusion without social inclusion: The consumption of information and communication technologies (ICTs) within homeless subculture in Scotland. The Journal of Community Informatics, 1(2), 116-133. 
Caton, C. L., Dominguez, B., Schanzer, B., Hasin, D. S., Shrout, P. E., Felix, A., ... \& Hsu, E. (2005). Risk factors for long-term homelessness: Findings from a longitudinal study of first-time homeless single adults. American Journal of Public Health, 95(10), 1753-1759. DOI: 10.2105/AJPH.2005.063321.

Chiu, S., Redelmeier, D. A., Tolomiczenko, G., Kiss, A., \& Hwang, S. W. (2009). The health of homeless immigrants. Journal of Epidemiology and Community Health, 63, 943-948. http://dx.doi.org/10.1136/jech.2009.088468

Christensen, I. \& Vinther, H. (2005) Exit from Homelessness. International Journal of Mental Health, 34, 3, 3-34.

Dworsky, A., Napolitano, L., \& Courtney, M. (2013). Homelessness during the transition from foster care to adulthood. American Journal of Public Health, 103(S2), S318-S323. DOI: 10.2105/AJPH.2013.301455

Edgar, B., Doherty, J., \& Meert, H. (2004). Immigration and homelessness in EuropeFEANTSA Research. Saint-Josse-ten-Noode. Belgium: FEANTSA Foundation.

Eyrich-Garg, K.M. (2010). Mobile phone technology: A new paradigm for the prevention, treatment, and research of the non-sheltered "street" homeless? Journal of Urban Health, 87 (3), 365-380.

Fazel, M., Wheeler, J., \& Danesh, J. (2005). Prevalence of serious mental disorder in 7000 refugees resettled in western countries: A systematic review. The Lancet, 365, $1309-$ 1314. http://dx.doi.org/10.1016/S0140-6736(05)61027-6

Guillén, A., Marín-Martín, C., Panadero, S., \& Vázquez, J.J. (in press). Substance use, stressful life events and mental health: A longitudinal study among homeless women in Madrid (Spain). Addictive Behaviors. DOI: 10.1016/j.addbeh.2019.106246.

Gelberg, L., Browner, C. H., Lejano, E., \& Arangua, L. (2004). Access to women's health care: A qualitative study of barriers perceived by homeless women. Women \& Health, 40(2), 87-100. DOI: doi.org/10.1300/J013v40n02_06

Greenberg, G.A. \& Rosenheck, R.A. (2009). Correlates of past homeless in the National Epidemiological Survey on Alcohol and Related Conditions. Administration and Policy in Mental Health and Mental Health Services Research, 37, 357-366. DOI: 10.1007/s 10488-009-0243-x.

INE (2018).

Accesible

en http://www.ine.es/jaxi/Datos.htm?path=/t20/e245/p08/10/\&file=03005.px

Kim, T. W., Kertesz, S. G., Horton, N. J., Tibbetts, N., \& Samet, J. H. (2006). Episodic homelessness and health care utilization in a prospective cohort of HIV-infected persons with alcohol problems. BMC Health Services Research, 6(1), 19. DOI: doi.org/10.1186/1472-6963-6-19

Lam, J. A., \& Rosenheck, R. (1998). The effect of victimization on clinical outcomes of homeless persons with serious mental illness. Psychiatric Services, 49, $678-683$. http://dx.doi.org/10.1176/ps.49.5.678

Leonori, L., Muñoz, M., Vázquez, C., Vázquez, J.J., Bravo, M., Nuche, M., Brandt, P., Bento A., \& Horenbek, B. (2000). The mental health and social exclusion European network: A research activity report on European homeless citizens. European Psychologist, 5(3), 245-251. DOI: 10.1027//1016-9040.5.3.245.

Lewis, J. H., Andersen, R. M., \& Gelberg, L. (2003). Health care for homeless women. Journal of General Internal Medicine, 18(11), 921-928. DOI: doi.org/10.1046/j.15251497.2003.20909.x

Lindert, J., Ehrenstein, O. S., Priebe, S., Mielck, A., \& Brähler, E. (2009). Depression and anxiety in labor migrants and refugees - A systematic review and meta-analysis. Social Science \& Medicine, 69, 246 -257. http://dx.doi.org/10.1016/j.socscimed.2009.04.032 
Marsapt, M. (2000). An advantage with limits. The lower risk for women of becoming homeless. Population, 12, 1-45.

Muñoz, M., Vázquez, C., \& Vázquez, J.J. (2004). A comparison between homeless, domiciled and vulnerable populations in Madrid. Population, 59 (1), 129-141.

Navarro-Lashayas, M. A., \& Eiroa-Orosa, F. J. (2017). Substance use and psychological distress is related with accommodation status among homeless immigrants. American Journal of Orthopsychiatry, 87(1), 23. DOI: dx.doi.org/10.1037/ort0000213

North, C. S., \& Smith, E. M. (1993). A comparison of homeless men and women: Different populations, different needs. Community mental health journal, 29(5), 423-431. DOI: doi.org/10.1007/BF00754410.

Nyamathi, A., Leake, B., Keenan, C., \& Gelberg, L. (2000). Type of social support among homeless women: Its impact on psychosocial resources, health and health behaviors, and use of health services. Nursing Research, 49(6), 318-326. DOI: dx.doi.org/10.1097/00006199-200011000-00004.

O'Grady, B. \& Gaetz, S. (2004). Homelessness, gender and subsistence: The case of Toronto street youth. Journal of Youth Studies, 7(4), 397-416. DOI: doi.org/10.1080/1367626042000315194

Okamoto, Y. (2007). A comparative study of homelessness in the United Kingdom and Japan. Journal of Social Issues, 63(3), 525-542. DOI: doi.org/10.1111/j.15404560.2007.00522.x

Panadero, S., Martín, R.M., \& Vázquez, J.J. (2018). Suicide attempts and stressful life events among homeless people in Madrid (Spain). Journal of Community and Applied Social Psychology, 28(4), 200-212. DOI: 10.1002/casp.2351.

Panadero, S., Guillén, A.I. \& Vázquez, J.J. (2015). Happiness in the street. Overall happiness among homeless people in Madrid (Spain). American Journal of Orthopsychiatry, 85(4), 324-330. DOI: dx.doi.org/10.1037/ort0000080.

Panadero, S., Vázquez, J.J. \& Martín, R.M. (2017). Alcohol, poverty and social exclusion: Alcohol consumption among the homeless and those at risk of social exclusion in Madrid. Adicciones, 29(1), 33-36. DOI: 10.20882/adicciones.830.

Parker, D. (2010). Housing as an intervention on hospital use: Access among chronically homeless persons with disabilities. Journal of Urban Health, 87(6), 912-919. DOI: doi.org/10.1007/s11524-010-9504-y.

Piliavin, I., Wright, B., \& Mare, R. (1996) Exits from and returns to homelessness. Social Service Review, 70, 33-57. DOI: doi.org/10.1086/604164.

Robertson, M.; Zlotnick, C.; \& Westerfelt, A. (1997). Drug use disorders and treatment contact among homeless adults in Alameda County, California. American Journal of Public Health, 87(2), 221-28. DOI: 10.2105/AJPH.87.2.221

Roca, P; Panadero, S., Rodríguez, S.I., Martín, R.M. \& Vázquez, J.J. (2019). Revolving door to homelessness. The influence of health, alcohol consumption and stressful life events on the number of episodes of homelessness. Anales de Psicología, 32 (5), 175-180

Rokach, A. (2005). Private lives in public places: Loneliness of the homeless. Social Indicators Research, 72(1), 99-114. DOI: doi.org/10.1007/s11205-004-4590-4

Ryan, G. W., Stern, S. A., Hilton, L., Tucker, J. S., Kennedy, D. P., Golinelli, D., \& Wenzel, S. L. (2009). When, where, why and with whom homeless women engage in risky sexual behaviors: a framework for understanding complex and varied decision-making processes. Sex Roles, 61(7-8), 536-553. DOI: doi.org/10.1007/s11199-009-9610-z.

Shaheen, G., \& Rio, J. (2007). Recognizing work as a priority in preventing or ending homelessness. The journal of primary prevention, 28(3-4), 341-358. DOI: doi.org/10.1007/s10935-007-0097-5. 
Suarez, A., Berrios, A., Bonilla, E., \& Vázquez, J.J. (2018). Homeless people in Nicaragua: A point-in-time count in León. Journal of International Development, 30(1), 155-158. DOI: 10.1002/jid.3303.

Thomas, G. \& Wyatt, S. (2000). Access is not the only problem: Using and controlling the Internet. In S. Wyatt, F. Henwood, N. Miller \& P. Senker (Eds.), Technology and inequality: Questioning the information society (pp. 21-45). London: Routledge.

Vázquez, J.J., Berrios, A., Bonilla, E., \& Suarez, A. (2019a). Homeless people in León (Nicaragua): Conceptualizing and measuring homelessness in a developing country. American Journal of Orthopsychiatry, 89(2), 296-303 DOI: dx.doi.org/10.1037/ort0000336

Vázquez, J.J. \& Panadero, S. (2016). Chronicity and pseudo inheritance of social exclusion: Differences according to the poverty of the family of origin among trash pickers in León (Nicaragua). Human Rights Quarterly, 38(2), 379-390. DOI: 10.1353/hrq.2016.0037.

Vázquez, J.J. \& Panadero, S. (2019). Suicidal attempts and stressful life events among women in a homeless situation in Madrid (Spain). American Journal of Orthopsychiatry, 89(2), 304-311.

Vázquez, J.J., Panadero, S. \& Pascual, I. (2019b). The particularly vulnerable situation of women living homeless in Madrid (Spain). Spanish Journal of Psychology, 22, e52. DOI: $10.1017 /$ sjp. 2019.58

Vázquez, J.J., Panadero, S. \& Rivas, E. (2015). Happiness among poor women victims of intimate partner violence in Nicaragua. Social Work in Public Health, 30(1), 18-29. Doi: 10.1080/19371918.2014.938389.

Vázquez, J.J., Panadero, S. \& Zúñiga, C. (2017). Content and uniformity of stereotypes and meta-stereotypes of homeless people in Madrid (Spain). Journal of Community Psychology, 45(1), 128-137. DOI: 10.1002/jcop.21836

Vázquez, J.J., Panadero, S., Martín, R.M. \& Díaz-Pescador, V. (2015). Access to new information and communication technologies among homeless people in Madrid (Spain). Journal of Community Psychology, 43(3), 338-347. Doi: 10.1002/jcop.21682.

Vázquez, J.J., Suarez, A., Berrios, A., \& Panadero, S. (2019c). Stressful life events among homeless people in León (Nicaragua): Quantity, Types, Timing, and Perceived Causality. Journal of Community Psychology, 47(1), 176-185 DOI: doi.org/10.1002/jcop.22102.

Wenzel, S. L., Leake, B. D., \& Gelberg, L. (2000). Health of homeless women with recent experience of rape. Journal of General Internal Medicine, 15(4), 265-268. DOI: doi.org/10.1111/j.1525-1497.2000.04269.x

Zlotnick, C.; Robertson, M.; \& Lahiff, M. (1999) Getting off the streets: Economic resources and residential exits from homelessness. Journal of Community Psychology, 27, 209-24. DOI: doi.org/10.1002/(SICI)1520-6629(199903)27:2<209::AID-JCOP8>3.0.CO;2-2.

Zugazaga, C. (2004). Stressful life event experiences of homeless adults: A comparison of single men, single women, and women with children. Journal of Community Psychology, 32(6), 643-654. DOI: /doi.org/10.1002/jcop.20025. 